University of Nebraska - Lincoln

DigitalCommons@University of Nebraska - Lincoln

Public Health Resources

Public Health Resources

2005

Evaluating current policy for detecting mosaicism in amniotic fluid cultures: implications for current cell counting practices

\author{
Samuel P. Caudill \\ Centers for Disease Control and Prevention, spc1@cdc.gov \\ Daniel L. Van Dyke \\ Henry Ford Hospital \\ Andrew T. L. Chen \\ Centers for Disease Control and Prevention \\ John A. Reidy \\ Centers for Disease Control and Prevention \\ Paul S. Ing \\ Boys Town National Research Hospital \\ See next page for additional authors
}

Follow this and additional works at: https://digitalcommons.unl.edu/publichealthresources

Part of the Public Health Commons

Caudill, Samuel P.; Van Dyke, Daniel L.; Chen, Andrew T. L.; Reidy, John A.; Ing, Paul S.; Schwartz, Stuart; and Vance, Gail H., "Evaluating current policy for detecting mosaicism in amniotic fluid cultures:

implications for current cell counting practices" (2005). Public Health Resources. 240.

https://digitalcommons.unl.edu/publichealthresources/240

This Article is brought to you for free and open access by the Public Health Resources at DigitalCommons@University of Nebraska - Lincoln. It has been accepted for inclusion in Public Health Resources by an authorized administrator of DigitalCommons@University of Nebraska - Lincoln. 
Authors

Samuel P. Caudill, Daniel L. Van Dyke, Andrew T. L. Chen, John A. Reidy, Paul S. Ing, Stuart Schwartz, and Gail H. Vance 


\title{
Evaluating current policy for detecting mosaicism in amniotic fluid cultures: implications for current cell counting practices ${ }^{\ddagger}$
}

\author{
Samuel P. Caudill ${ }^{1, *,}$, Daniel L. Van Dyke ${ }^{2}$, Andrew T. L. Chen ${ }^{1}$, John A. Reidy ${ }^{1}$, \\ Paul S. Ing ${ }^{3}$, Stuart Schwartz ${ }^{4}$ and Gail H. Vance ${ }^{5}$ \\ ${ }^{1}$ Centers for Disease Control and Prevention, Atlanta, GA, U.S.A. \\ ${ }^{2}$ Henry Ford Hospital, Detroit, MI, U.S.A. \\ ${ }^{3}$ Boys Town National Research Hospital, Omaha, Nebraska, U.S.A. \\ ${ }^{4}$ Case Western Reserve University, Cleveland, OH, U.S.A. \\ ${ }^{5}$ Indiana University, Indianapolis, IN, U.S.A.
}

\begin{abstract}
SUMMARY
Chromosomal mosaicism is one of the most vexing problems for clinical cytogenetic laboratories and personnel time used for analysis at the microscope is one of the principle costs in cytogenetic laboratories. We use data collected from 26 cytogenetic laboratories to evaluate whether the American College of Medical Genetics guidelines for minimum number of cells to count to exclude mosaicism in amniotic fluid specimens is appropriate. An accurate estimate of the number of mosaics that are missed by current cell counting practices is an important step in this process. Thus, we present a new method for estimating the number of mosaics that are missed and we use computer simulation to evaluate this new method. Our results indicate that if the clinical significance of mosaicism is suspected to be minimal for certain cytogenetic anomalies when the percentage of abnormal cells is 15 per cent or less, then it may be sufficient to use a 15-cell counting-rule-for-detection along with a minimum total cell count of 30 regardless of whether abnormal cells or normal cells are in the minority. Published in 2005 by John Wiley \& Sons, Ltd.
\end{abstract}

KEY WORDS: binomial distribution; cytogenetics; mosaicism; mosaic heterogeneity

\section{INTRODUCTION}

In cytogenetics, when an individual has two or more cell lines with differing chromosomal constituents, the individual is referred to as a mosaic. Detection of a mosaic case is determined by counting a specified number of cells. Hook [1] published tables indicating the number of cells that must be counted to exclude a specified percent mosaicism with 90, 95, and 99 per

\footnotetext{
* Correspondence to: Samuel P. Caudill, Centers for Disease Control and Prevention, Clinical Chemistry Branch, 4770 Buford Highway NE MS-F25, Atlanta, GA 30341-3724, U.S.A.

†E-mail: spc1@cdc.gov

¥This article is a U.S. Government work and is in the public domain in the U.S.A.
} 
cent confidence. His tables are based on binomial sampling theory applied to the problem of mosaic case identification. Since the proportion of abnormal cells varies greatly among mosaics, the likelihood of actually detecting a mosaic case depends upon each individual's true percent mosaicism and upon the number of cells counted to exclude mosaicism [1]. Thus, even when a constant number of cells to exclude mosaicism is counted in each subject sample, the error in estimates of the true numbers of mosaic cases (among the total number of subject samples tested) will depend upon the range of mosaic percentages among case subjects. Additional sources of error can result if a different number of cells to exclude mosaicism is counted in each sample or if a different total number of cells is counted.

One purpose of the CYTO2000 initiative $[2,3]$ was to use data collected from clinical cytogenetic laboratories to consider whether the American College of Medical Genetics (ACMG) guidelines [4] for minimum number of cells to count to exclude mosaicism in amniotic fluid specimens is appropriate. For the in situ technique, these guidelines recommend counting 'a minimum of 15 cells from at least 15 colonies ( 10 cells if 15 are not available), distributed as equally as possible between at least two independently established cultures'. Type 3 (or true) mosaicism 'occurs when two or more cell lines are in separate cultures from a sample and all cell lines must have two or more cells with the same karyotype. Mosaicism is first suspected upon detection of a cell with a different karyotype than the first line. Mosaicism is not confirmed until another cell with the second karyotype is observed' [3]. If no new karyotype (i.e. a cell differing from the first cell examined) is detected once the countingrule-for-detection ( 15 cells from 15 colonies) has been reached, counting is stopped and the sample is considered non-mosaic. If at least one cell with a new karyotype is detected by the counting-rule-for-detection, counting continues. For the sample to be considered a confirmed mosaic case, at least 2 cells (i.e. one more cell than is required for detection) with the same karyotype must be detected.

In the first CYTO2000 study [3] of amniotic fluid mosaic cases collected from 26 cytogenetic laboratories, simple calculations based on binomial theory were used to estimate the true number of cases represented by the subset of cases $(n=433)$ detected by the 15 th cell counted. In that paper, the estimate of the true number of cases was based on the probability of detection (rather than detection and confirmation) of the second cell line. Thus, the numbers of missed cases were underestimated (especially when the percent mosaicism was low) because the estimation method assumed that all detected cases were used, whereas only cases detected and confirmed were used; and because the joint probability of detection and confirmation is never larger than the probability of detection. In this paper, we describe and evaluate an improved method for estimating the true number of cases based on the joint probability of detection by the $K$ th counted cell and confirmation by the $M$ th counted cell, where $K$ is the number of cells counted to exclude mosaicism and $M$ is the total number of cells counted. We use computer simulation (see Appendix) to evaluate the accuracy of estimates obtained by this new method. Finally, we use our estimates of the numbers of missed mosaic cases to evaluate current cell counting practices (which are based on the ACMG guidelines).

\section{MATERIALS AND METHODS}

We examine the data set presented in the first CYTO2000 study [3] of amniotic fluid mosaic cases. This data set consists of 442 cases with two cell lines detected by in situ methods in 
Table I. Simulation results for percentage error in an estimate of the true number of cases by per cent mosaicism and total cell count. A 15-cell counting-rule-for-detection was used for mosaic case detection.

\begin{tabular}{lccrc}
\hline & & \multicolumn{2}{c}{ Percentage error in estimate of true number of cases } \\
\cline { 3 - 5 } Percent mosaicism* & True number of cases & $20^{\dagger}$ & 30 & 40 \\
\hline$>0-10$ & 50 & -27.7 & -11.7 & -3.7 \\
$>10-15$ & 50 & -6.0 & 0.5 & 1.6 \\
$>15-20$ & 50 & 0.6 & 1.2 & 0.6 \\
$>20-30$ & 50 & 0.3 & -0.6 & -0.1 \\
$>30-40$ & 50 & -0.2 & -0.0 & -0.0 \\
$>40-50$ & 50 & -0.0 & 0.0 \\
\hline
\end{tabular}

* Percentages of abnormal cells above 50 per cent are translated into mosaic percentages by subtraction from 100 per cent.

${ }^{\dagger}$ The numbers 20,30 , and 40 are the total cell counts.

26 cytogenetic laboratories. Since it was not possible to determine (for each case) the actual number of cells counted to exclude mosaicism, we assume that a minimum of 15 cells from 15 colonies in at least two cultures were counted for in situ cultures as recommended by the ACMG guidelines [4]. According to this counting rule, which we will refer to as a 15-cell 'counting-rule-for-detection,' if 15 cells/colonies are counted and no evidence of mosaicism is detected, the analysis is stopped.

To evaluate the new method for estimating the true number of cases we assumed: (1) that the proportion of abnormal cells in culture accurately reflects the proportion of abnormal cells in amniotic fluid, (2) colonies that grow from cells in amniotic fluid can be considered independent, (3) cells examined represent a random sample of all cells that could have been scored, and (4) there is a minimum total number of cells a cytogeneticist will count before discontinuing pursuit of confirmation of suspected cases.

We approached the mosaic case detection problem in terms of both percentage (or proportion) of abnormal cells and percent mosaicism. (Note: The percentage of abnormal cells can range from 0 to 100 per cent, whereas the percent mosaicism can only range from 0 to 50 per cent, since any percentage of abnormal cells that exceeds 50 per cent corresponds to a percentage of normal cells that is less than 50 per cent.) Considering only percent mosaicism would have precluded evaluation of whether cytogeneticists are likely to count more cells/colonies when abnormal cells are in the minority than when normal cells are in the minority and whether they are in turn less likely to miss low-level mosaics that are predominantly normal rather than those that are predominantly abnormal. By distinguishing between these two types of mosaics, we were able to focus attention on missed cases that are more likely to be clinically significant due to counting too few cells.

Cases were stratified based on observed percentage abnormal to minimize errors caused by variation in the percentage of abnormal cells among individuals. The percent abnormal strata chosen (see Tables I and II) correspond to the percent mosaicism strata used in the first CYTO2000 study [3]. A description of the method for estimating the true number of cases follows:

The total number of mosaic cases in each stratum is estimated by forming the ratio of the number of confirmed cases to the joint probability of case detection and confirmation based on a minimum count of $K$ cells to exclude mosaicism and a total count of $M$ cells. Thus 
Table II. Observed and estimated number of mosaic cases detected from in situ cultures by percent mosaicism and type of cell.

\begin{tabular}{|c|c|c|c|c|c|}
\hline \multirow[b]{2}{*}{$\begin{array}{l}\text { Percent } \\
\text { mosaicism }\end{array}$} & \multirow[b]{2}{*}{$\begin{array}{l}\text { Type of cell } \\
\text { in minority* }\end{array}$} & \multicolumn{2}{|c|}{$\begin{array}{l}\text { Observed number of } \\
\text { cases detected }\end{array}$} & \multirow[b]{2}{*}{$\begin{array}{l}\text { Estimated true number } \\
\text { of mosaic cases }\end{array}$} & \multirow[b]{2}{*}{$\begin{array}{l}\text { Estimated percentage } \\
\text { of missed cases }\end{array}$} \\
\hline & & By 15 th cell ${ }^{\dagger}$ & Total $^{\ddagger}$ & & \\
\hline \multirow[t]{3}{*}{$>0-10$} & Abnormal & 44 & 45 & 75 & 44 \\
\hline & Normal & 7 & 9 & 22 & \\
\hline & abn1/abn2 & 2 & 3 & 4 & \\
\hline \multirow[t]{3}{*}{$>10-15$} & Abnormal & 45 & 47 & 53 & 15 \\
\hline & Normal & 8 & 8 & 12 & \\
\hline & abn1/abn2 & 5 & 6 & 7 & \\
\hline \multirow[t]{3}{*}{$>15-20$} & Abnormal & 51 & 52 & 55 & 8 \\
\hline & Normal & 8 & 8 & 9 & \\
\hline & abn1/abn2 & 9 & 9 & 11 & \\
\hline \multirow[t]{3}{*}{$>20-30$} & Abnormal & 61 & 61 & 62 & 3 \\
\hline & Normal & 19 & 19 & 20 & \\
\hline & abn1/abn2 & 9 & 9 & 10 & \\
\hline \multirow[t]{3}{*}{$>30-40$} & Abnormal & 48 & 48 & 49 & 2 \\
\hline & Normal & 33 & 34 & 34 & \\
\hline & abn1/abn2 & 16 & 16 & 17 & \\
\hline \multirow[t]{3}{*}{$>40-50$} & Abnormal & 45 & 45 & 46 & 4 \\
\hline & Normal & 16 & 16 & 17 & \\
\hline & abn1/abn2 & 7 & 7 & 8 & \\
\hline Total & & 433 & 442 & 511 & 14 \\
\hline
\end{tabular}

*abn1/abn2 refers to mosaic cases in which two different types of abnormal cells were detected, but no normal cells were detected.

${ }^{\dagger}$ Number of mosaic cases detected by the 15 th cell counted from in situ cultures.

${ }^{\ddagger}$ Total number of mosaic cases detected from in situ cultures.

$\S$ The expected true number of mosaic cases is based on the assumption that a constant 15-cell counting-rule-for-detection was used for all cases. The total number of cells counted is assumed to be equal to the median of the total number of cells counted for all confirmed cases in the stratum. Further adjustments were made to the estimates when the percent mosaicism was less than 15 per cent to account for the expected error in estimation as indicated in Table I.

assuming that detected cases are based on a constant counting-rule-for-detection of $K$ cells and a total count of $M$ cells, the expected true number of cases in the $i$ th stratum, can be estimated by

$$
N_{T}=N_{\mathrm{dc}(K)} /\left[1-\left(1-P_{\mathrm{abn}}\right)^{K}-P_{\mathrm{abn}}^{K}-K P_{\mathrm{abn}}\left(1-P_{\mathrm{abn}}\right)^{(M-1)}-K P_{\mathrm{abn}}^{(M-1)}\left(1-P_{\mathrm{abn}}\right)\right]
$$

where $N_{\mathrm{dc}(K)}$ is the actual number of mosaic cases detected by the $K$ th cell counted and confirmed by the $M$ th counted cell for stratum $i, P_{\mathrm{abn}}$ is the observed median proportion of abnormal cells detected and confirmed for stratum $i$, and $M$ is the total number of cells counted.

Simulation: To evaluate the new estimation method, we simulated cases and non-cases with percentages of abnormal cells within each of six strata corresponding to the six strata used in the first CYTO2000 study [3]. These mosaic strata are defined as follows: (0-10]; 
(10-15]; (15-20]; (20-30]; (30-40]; and (40-50], where brackets indicate inclusion of the adjacent number and parentheses indicate exclusion of the adjacent number. Percentages of abnormal cells above 50 per cent are translated into mosaic percentages by subtraction from 100 per cent. In the simulation experiment, we used a constant counting-rule-for-detection of 15. To determine the effect of the total number of cells counted (in confirmed cases) on the accuracy of the estimation methods we let the total cell count take values 20,30, and 40 . (Note: an average total count of 32 cells was observed in the first CYTO2000 study [3].) A detailed explanation of the methods used to conduct the simulation experiment is presented in the appendix.

\section{RESULTS}

The simulation results presented in Table I were generated using a constant counting-rulefor-detection of 15 and total cell counts of 20,30, or 40. The true number (50) of cases in each stratum appears (we also performed simulations with 25 and 100 cases in each stratum; results not shown) to have little effect on the accuracy of the estimation method. Increasing the total cell count beyond 40 does not result in appreciable error reduction for the estimation method, but lowering it to 20 could decrease the accuracy of the estimation method when the per cent mosaicism is 15 per cent or less.

Table II displays actual results obtained from an analysis of 442 cases of amniotic fluid mosaicism collected from 26 cytogenetic laboratories from in situ cultures. The strata are grouped according to percent mosaicism to facilitate comparison when abnormal cells versus normal cells are in the minority. Also included in the table are mosaic cases in which two different types of abnormal cells were detected, but no normal cells were detected. The observed numbers of detected mosaic cases in each stratum are presented along with the estimated true numbers obtained by the new estimation method. (Note: a constant counting-rule-for detection of 15 was apparently not used for 4.5 per cent $(20$ of 442$)$ of the detected cases. These 20 cases consisted of nine cases not detected until after the 15th cell was counted and 11 cases detected when fewer than 15 cells/colonies were analysed. These 20 cases were used, however, in calculating the median percentage mosaicism for each stratum.)

Table III displays the distribution of total number of cells/colonies counted for each of the percentage mosaicism strata. As was done in Table II, the strata are grouped according to percent mosaicism to facilitate comparison of distributions when abnormal cells versus normal cells are in the minority. Kruskal-Wallis two-sample tests [5] to compare distributions of total numbers of cells counted for mosaic categories with abnormal cells in the minority versus those with normal cells in the minority, suggest that cytogeneticists may tend to count a higher total number of cells/colonies when abnormal cells are in the minority than when normal cells are in the minority and the percent mosaicism is less than 15 per cent. Results were also statistically significant when the percent mosaicism was between 20 and 30 per cent.

The results discussed in the previous section raise a question about whether missed mosaics are less likely when abnormal cells are in the minority than when they are in the majority due to the fact that cytogeneticists tend to count a higher total number of cells when abnormal cells are in the minority. To test this hypothesis we used the estimated true numbers of mosaic cases (fifth column of Table II) to estimate percentages of missed cases when abnormal cells 
Table III. Distribution of total number of cells counted by percent mosaicism and type of cell in minority.

\begin{tabular}{lccccccc}
\hline & & \multicolumn{7}{c}{ Selected percentiles of total number of cells counted } \\
\cline { 3 - 7 } Percent mosaicism & $\begin{array}{c}\text { Type of cell } \\
\text { in minority }\end{array}$ & Min & 25 th & Median & 75 th & Max & $P^{*}$ \\
\hline \multirow{2}{*}{$>0-10$} & Abnormal & 20 & 34.0 & 40.0 & 51.0 & 98 & 0.0102 \\
& Normal & 10 & 20.0 & 27.0 & 30.0 & 110 & 2 \\
$>10-15$ & Abnormal & 15 & 21.0 & 30.0 & 38.0 & 81 & 0.0069 \\
& Normal & 15 & 16.0 & 20.5 & 23.5 & 33 & 9 \\
$>15-20$ & Abnormal & 15 & 20.0 & 28.0 & 39.5 & 79 & 0.5067 \\
& Normal & 10 & 20.5 & 23.5 & 32.0 & 40 & 7 \\
$>20-30$ & Abnormal & 15 & 20.0 & 28.0 & 35.0 & 71 & 0.0179 \\
& Normal & 12 & 19.0 & 20.0 & 25.0 & 50 & 9 \\
$>30-40$ & Abnormal & 13 & 20.0 & 25.5 & 32.0 & 70 & 0.2040 \\
& Normal & 13 & 17.0 & 21.0 & 27.0 & 61 & 0 \\
& Abnormal & 7 & 19.0 & 21.0 & 29.0 & 100 & 0.1821 \\
& Normal & 11 & 17.5 & 20.0 & 22.5 & 36 & 1 \\
\hline
\end{tabular}

* One degree of freedom Chi-square significance resulting from Kruskal-Wallis two-sample tests [5] to compare distributions of total numbers of cells counted for mosaic categories with abnormal cells in the minority versus those with normal cells in the minority.

versus normal cells are in the minority. When the percent mosaicism is 15 per cent or less, 28 per cent $(0.28=\{[75+53]-[45+47]\} /[75+53])$ of cases appear to be missed when abnormal cells are in the minority and 50 per cent $(0.50=\{[22+12]-[9+8]\} /[22+12])$ appear to be missed when normal cells are in the minority $(p=0.01)$. Differences were not significant when the percent mosaicism was higher than 15 per cent. These results suggest that missed mosaics are more likely when normal cells are in the minority than when abnormal cells are in the minority and the percent mosaicism is 15 per cent or less.

\section{DISCUSSION AND CONCLUSIONS}

In order to evaluate the American College of Medical Genetics guidelines for minimum number of cells to count to exclude mosaicism in amniotic fluid cultures, an accurate estimate of the number of mosaics that are missed by current cell counting practices must be obtained. In this paper, we demonstrate an improved method for estimating true numbers of missed mosaic cases that takes into account the total number of cells counted as well as the number of cells counted to exclude mosaicism. Our method incorporates the use of data pooled from multiple laboratories counting different total numbers of cells/colonies per case. When estimating true numbers of mosaic cases, stratification of observed cases based on observed percent abnormal cells is used to minimize error due to mosaic heterogeneity among samples.

The results of our analyses suggest (when the mosaic percentage is less than 15 per cent) that because cytogeneticists tend to count more cells/colonies when abnormal cells are in the minority than when normal cells are in the minority, they are more likely to miss cases with normal cells in the minority. The curves in Figure 1, which are based on theoretic calculations similar to those used to derive equation (1) in the Materials and Methods section, demonstrate 


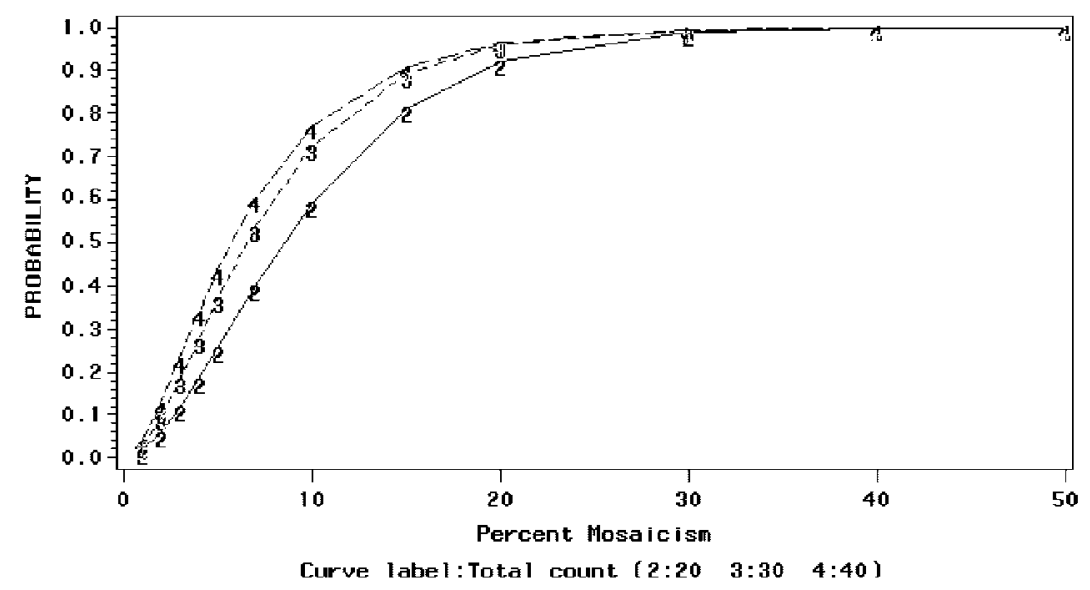

Figure 1. Theoretic probability of case confirmation based on a total cell count of 20,30 , or 40 and a counting-rule-for-detection of 15 .

the relationship between true percent mosaicism and probability of case confirmation based on a total cell count of 20,30 , or 40 and a counting-rule-for-detection of 15 . These results indicate that at least 90 per cent of cases that are 15 per cent or more mosaic will be detected and confirmed by using a 15-cell counting-rule-for-detection along with a minimum total cell count of 30 . It is also clear that counting beyond 30 cells is not cost-effective since it will only result in minimal gains in the numbers of confirmed cases. This observation is consistent with the recommendation of Hsu et al. [6] when diagnosis of true mosaicism has little impact and is not cost-effective. Thus, if future studies were to indicate, for example, that the clinical significance of mosaicism is suspected to be minimal for certain cytogenetic anomalies when the percentage of abnormal cells is 15 per cent or less, then it may be sufficient to use a 15-cell counting-rule-for-detection along with a minimum total cell count of 30 regardless of whether abnormal cells or normal cells are in the minority.

\section{APPENDIX}

Each simulation experiment was accomplished (using version 6.12 of SAS) by first generating $N$ sets of $N_{\mathrm{C}}$ (where $N_{\mathrm{C}}$ represents the total cell count and takes values 20,30 or 40) observations in each of six strata representing mosaic categories $(1:>0-0.10 ; 2$ : $>0.10-0.15$; 3: $>0.15-0.20 ; 4:>0.20-0.30 ; 5:>0.30-0.40$; and $6:>0.40-0.50)$. A uniform $(0,1)$ random number generator was used to assign a value of 0 or 1 to each of the $N_{\mathrm{C}}$ observations in each of the $N$ sets based on whether the uniform random number was less than or greater than the intended mosaic proportion of the stratum. If at least one observation with the value 1 occurred among the first 15 of the $N_{\mathrm{C}}$ observations in a set and at least one additional observation with the value 1 occurred among the first $N_{\mathrm{C}}$ observations, then all $N_{\mathrm{C}}$ observations in that set were retained for computation of an observed percentage of abnormal cells for the case represented by this set. If no observation with the value 1 (i.e. all of the first 15 observations were zeroes) occurred among the first 15 of the $N_{\mathrm{C}}$ observations in a set or if only one 
observation with the value 1 occurred among all $N_{\mathrm{C}}$ observations, then this entire set of $N_{\mathrm{C}}$ observations was dropped and, therefore, treated as a non-case or a missed case. This process resulted in a range of observed mosaic percentages among cases within each stratum and a variable number of observed cases in each stratum. Separately for each stratum we compared the median number of confirmed mosaic cases to the true number of mosaic cases in the stratum. We repeated this process 1000 times to obtain 1000 simulated data sets for each of the six strata, each of three values of $N(25,50$, and 100), and each of the three values of $N_{\mathrm{C}}(20,30,40)$.

\section{ACKNOWLEDGEMENTS}

The authors acknowledge the contributions of the following persons for the use of their data sets or their participation in making the data sets available for analysis: Frederick R. Bieber, Phillip D. Buchanan, Andrew J. Carroll, Sau W. Cheung, Gordon DeWald, Roger P. Donahue, H. Allen Gardner, James Higgins, Lillian Y. F. Hsu, Mehdi Jamehdor, Caroline H. Laundon, Frederick W. Luthardt, James Mascarello, Kristin M. May, Jeanne M. Meck, Cynthia Morton, Shiva Patil, David Peakman, Mark J. Pettenati, Nagesh Rao, Warren G. Sanger, Deborah F. Saxe, Gurbax S. Sekhon, Gillian Bice, Herman E. Wyandt, Cheng W. Yu, Julie Zenger Hain, Patrick D. Storto, Nyla A. Heerema, and all of the laboratory personnel in all of the labs who contributed to the identification of these cases.

\section{REFERENCES}

1. Hook EB. Exclusion of chromosomal mosaicism: tables of 90, 95, and 99 per cent confidence limits and comments on use. American Journal of Human Genetics 1977; 29:94-97.

2. Chen ATL, Ing PS, Reidy JA, Schwartz S, Vance GH, Van Dyke DL. The ACMG CYTO2000 subcommittee? Genetics and Medicine 1998; 1(1):67.

3. Ing PS, Van Dyke DL, Caudill SP, Reidy JA, Bice G, Bieber FR, Buchanan PD et al. Detection of mosaicism in amniotic fluid cultures: a CYTO2000 collaborative study. Genetics in Medicine 1999; 1:94-97.

4. Standards and Guidelines for Clinical Genetics Laboratories, Section E4.1.3.2 (2nd edn). 1999; 14.

5. Kruskal WH, Wallis WA. Use of ranks on one-criterion variance analysis. Journal of the American Statistical Association 1952; 47:583-621.

6. Hsu LY, Kaffe S, Jenkins EC, Alonso L, Benn PA, David K, Hirschhorn K, Lieber E, Shanske A, Shapiro LR, Schutta E, Warburton D. Proposed guidelines for diagnosis of chromosome mosaicism in amniocytes based on data derived from chromosome mosaicism and pseudomosaicism studies. Prenatal Diagnosis 1992; 12:555-573. 